\title{
Response of dune activity on the Tibetan Plateau to near future climate change
}

\author{
Benli Liu ${ }^{1, *}$, Jianjun $\mathrm{Qu}^{1,2}$, Shichang Kang ${ }^{3}$ \\ ${ }^{1}$ Dunhuang Gobi Desert Ecological and Engineering Research Station, \\ Cold and Arid Regions Environmental and Engineering Research Institute, Chinese Academy of Sciences, Lanzhou 730000, \\ PR China \\ ${ }^{2}$ Gansu Center for Sand Hazard Reduction Engineering and Technology, Lanzhou 730000, PR China \\ ${ }^{3}$ State Key Laboratory of Cryospheric Sciences, Lanzhou 730000, PR China
}

\begin{abstract}
Four general circulation models (GCMs) under the moderate Representative Concentration Pathway (RCP) 4.5 emission scenario were used to evaluate the impact of climate change on monthly scale dune activity and desertification during the near future (2015-2035) in Anduo on the Tibetan Plateau (TP) of China. Dune activity was estimated by an improved index that uses the Penman-Monteith equation to account for comprehensive climate factors, including precipitation, air temperature, wind speed, humidity, and air pressure. Lower limits were used for the evapotranspiration values and the ratio of rainfall to evapotranspiration so that it was possible to calculate a dune activity index in the cold and dry winter months in the TP. The GCM outputs were transferred by statistical functions built from the control period (1966-2005), and the overlapping period of GCM projections and observations from 2006-2014 was used for error estimation. The results show that all GCMs captured the variation in dune activity well, although large differences in values were found. The statistical transferring of GCM outputs cannot reduce estimation error. The annual dune activity index is predicted to decrease by 7 to $9 \%$ during 2015-2035, implying that sand dunes will be easily stabilized in the future, but the 4 GCMs differ in January and February. If excessive surface disturbances can be controlled, the future environment in the studied area will be suitable for the reversal of the desertification trend, recovery of degraded land, and improvement of the living conditions for local herders.
\end{abstract}

KEY WORDS: Dune activity index - Penman-Monteith equation - General circulation models · $\mathrm{GCMs} \cdot$ Statistical transfer

\section{INTRODUCTION}

The effect of climate change has been widely considered by researchers and society, and the influence of climate change on desertification is of great concern (Sivakumar 2007, Wang et al. 2009). The Tibetan Plateau (TP), the highest and most extensive highland on the Earth, is undergoing rapid atmospheric warming and desertification (Yang et al. 2004, Feng et al. 2006, Kang et al. 2010). The elevated temperatures may contribute to more intense freezethaw action, glacial shrinkage, hydrological drought in the upper layer of the soil, and more aeolian mate-

${ }^{*}$ Corresponding author: liubenli@lzb.ac.cn rials (Cheng \& Wu 2007, Xue et al. 2009, Li et al. 2012, Yao et al. 2012). The dune activity problem on the plateau is a continual environmental threat, especially in Anduo County near Cuona Lake, because dunes can bury the Qinghai-Tibetan Railway and other facilities (Fig. 1) (Zhang et al. 2012). However, little research has investigated the response of dune activity and desertification to future climate change on the TP. It is not clear whether desertification will be accelerated by future warming or restrained by increased precipitation.

Some dune mobility indices have been developed to express the influence of climate change on wind

(C) The authors 2016. Open Access under Creative Commons by Attribution Licence. Use, distribution and reproduction are unrestricted. Authors and original publication must be credited. 


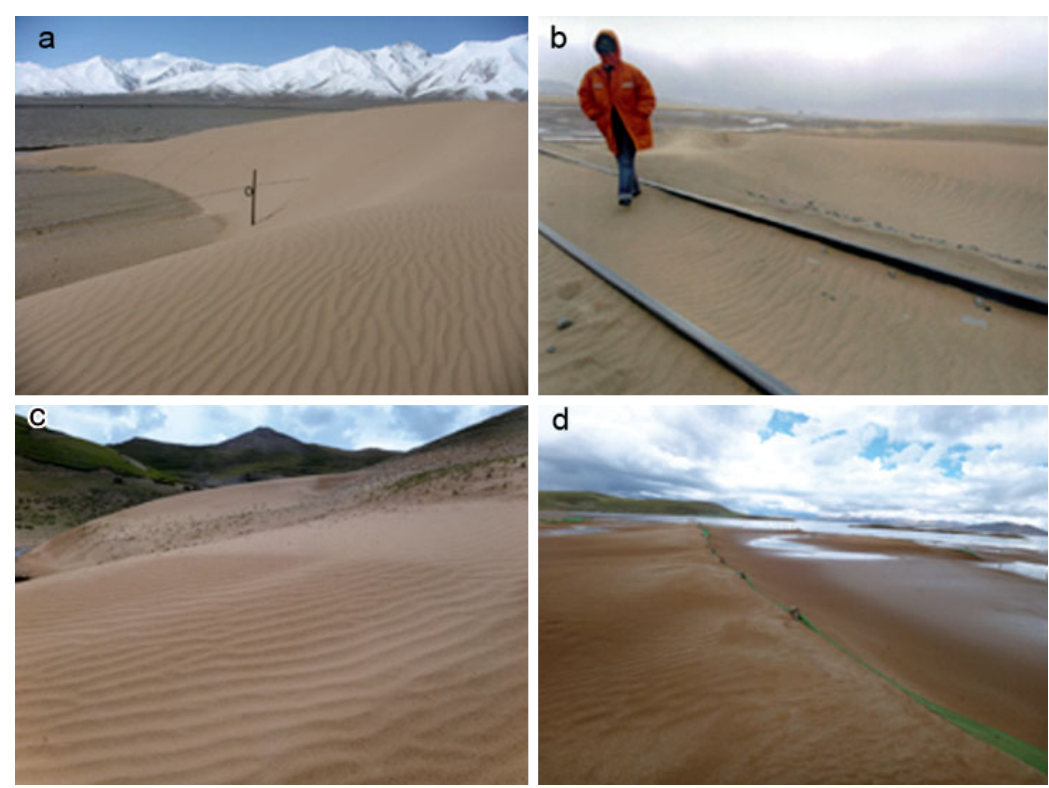

Fig. 1. Problems caused by wind-blown sand and dune mobility in Anduo County, Tibet. (a) Newly accumulated aeolian sands burying telegraph poles. (b) Blown sand deposited on the Qinghai-Tibetan Railway. (c) Degraded land becoming a bare sand surface. (d) A sand fence buried by shifting sand along Cuona Lake

erosion potential and desertification trends in a region. A commonly adopted index was modeled by Lancaster (1988):

$$
M=W /(P / P E T)
$$

where $M$ is the dimensionless dune activity index, and $W, P$, and $P E T$ are, respectively, the wind, precipitation, and potential evapotranspiration parameters that reflect the surface erodibility and wind erosivity conditions. Sand dunes would trend towards being active under the condition of a high $M$ value. The $W$ and $P$ parameters can be easily determined from meteorological data, but PET is more complex and critical in reflecting the land surface and climate conditions. PET was originally calculated using the Thornthwaite method, which assumes 0 evapotranspiration when temperatures drop below the freezing point. This index has been adopted to study the future changes in deserts and desertification from Africa to China using general circulation model (GCM) outputs (Thomas et al. 2005, Wang et al. 2009).

However, when a 0 PET is used, e.g. in the long cold season over the TP, the denominator in Eq. (1) is undefined. Thus, Eq. (1) is not practical. Additionally, temperature is considered to be the only climatic factor that influences evapotranspiration in the Thornthwaite method, but the complex nature of surface dryness conditions is not fully expressed. Moreover, the Thornthwaite method has proven to be unreli- able for dry conditions, including NW China (Chen et al. 2005). The dune activity index can be improved using a more realistic estimate of $P E T$.

A possible substitute for the Thornthwaite method for estimating $P E T$ is the Penman-Monteith equation. This equation has been increasingly used by researchers to obtain a more comprehensive estimation of PET that considers all parameters that govern energy exchange and latent heat flux (Fu \& Feng 2014, Gao et al. 2015, King et al. 2015). However, the Penman-Monteith equation does not address the cold temperature problem, and the author of the modified equation stated that 'the use of PET under such conditions is of limited value ...' (Allen et al. 1998, p. 209). Calculation with this method can result in $P E T$ values that are negative or close to 0 when longwave radiation from the surface is large, leading to negative or extremely large P/PET values. This problem was avoided in some previous studies by calculating the seasonal PET, but the PET and dune activity at a finer (monthly) scale is still of great interest because it allows the strong temporal changes in the surface characteristics and the desertification processes over the course of a year to be studied.

Another problem in predictive research that uses GCM data is the prediction deviation or error in the models. In over $40 \mathrm{GCMs}$, contrary predictions were made for at least some variables, demonstrating that derived predictions should not be based on a single $\mathrm{GCM}_{\text {; }}$ additionally, some researchers have taken the mean of the models (Collins et al. 2012, Jiang \& Tian 2013, Wang et al. 2014). It has also been implied that if individual GCM outputs are going to be used, they should be scaled or adjusted based on historical data (Zhang 2007). Due to the large spatial and temporal mismatches between historical and GCM data, many studies have been carried out to adjust or downscale the GCM single or multi-variable historical period data based on their statistical relationships with local observation variables, and the relationships were then applied to future predictions (Gunawardhana \& Kazama 2009, Selbig 2015). However, there is little work that evaluates the efficient adjustment of future GCM predictions in this manner. Some uncertainty analyses add tolerance to the future data, but these are not true error estimates of the GCM predictions (Fu \& Feng 2014). 
Here we used an improved dune activity index by calculating the PET using the Penman-Monteith method to study the intra-annual dune activity and desertification trends in a near future warming during 2015-2035 on the cold TP. Lower limits were applied to the PET and P/PET values to avoid extreme results in the cold and dry winter months. Four GCM projections were downscaled to the target location, and their deviations were considered by comparing the overlapping historical and prediction time period values. Anduo County in the central TP, where severe desertification has occurred in recent years, was chosen as a case study area.

\section{MATERIALS AND METHODS}

\subsection{Study area description}

Anduo County, located at $32^{\circ} 15^{\prime} \mathrm{N}, 91^{\circ} 40^{\prime} \mathrm{E}$ between the Tanglha and Nyenchen Tanglha Mountains, has an altitude of approximately $4800 \mathrm{~m}$, annual mean temperature of $-2.57^{\circ} \mathrm{C}$, multi-year average evaporation of ca. $1690 \mathrm{~mm}$, and annual mean wind speed of $4.03 \mathrm{~m} \mathrm{~s}^{-1}$. Records from the local meteorological station show that multi-year average precipitation is $446 \mathrm{~mm}, 70 \%$ of which occurs in the summer, $20 \%$ in the autumn, $9 \%$ in the spring, and only approximately $1 \%$ in the winter. The temperature rose $0.35^{\circ} \mathrm{C}$ per $10 \mathrm{yr}$ from 1966-2014 and $0.48^{\circ} \mathrm{C}$ per 10 yr from $1979-2014$ according to historical records, which are almost twice the reported global land surface air temperature increases in the CRUTEM and the Berkeley projections for the period 1951-2012 (Hartmann et al. 2013). In the winter season, the temperature increased $0.59^{\circ} \mathrm{C}$ per $10 \mathrm{yr}$ from $1966-2014$ and $0.70^{\circ} \mathrm{C}$ per 10 yr from 1979-2014, which was approximately $60 \%$ higher than the yearly averages. The warming on this remote plateau area is a clear response to the combined effects of climatic forcing variables, with little influence from non-climate variables, such as urbanization and fertilizer application. Meanwhile, precipitation has also increased during the recorded period at a rate of approximately $19.34 \mathrm{~mm}$ per decade, with some fluctuation, but $<2 \%$ of the increase occurred in the winter. The wind speed record shows a declining trend of $0.4 \mathrm{~m} \mathrm{~s}^{-1}$ per decade from 1966-2014. Alpine meadow degradation and aeolian desertification can be observed along valleys and roads, which mostly concentrate to the east of Cuona Lake (Fig. 1).

\subsection{Dune activity index}

In the dune activity index of Eq. (1), $W$ was originally represented by the percentage of the wind speed that was above the sand transport threshold, but this value is not a standard element from meteorological records or GCM outputs. Thus, $W$ was replaced by $U^{3}$, where $U$ is the third power of the mean monthly wind speed from meteorological observations; $U^{3}$ has been extensively employed in wind erosion and dune mobility research (Thomas et al. 2005, Wang et al. 2009). The rainfall factor $P=\left(P_{-1}\right.$ $\left.+P_{0}\right) / 2$ accounts for the prolonged effect of rainfall, where $P_{-1}$ is the amount of precipitation in the previous month and $P_{0}$ is the precipitation in the current month.

To estimate $P E T$, we replaced the original Thornthwaite method with the Penman-Monteith equation as described above. The Penman-Monteith equation has been recommended by the Food and Agriculture Organization of the United Nations as a standard method to calculate $P E T$, with its principles and procedures fully provided, following Allen et al. (1998):

$$
P E T=\Delta\left(R_{n}-G\right)+\rho_{a} c_{p} \frac{e_{s}-e_{a}}{r_{a}} / \lambda\left(\Delta+\gamma\left(1+\frac{r_{s}}{r_{a}}\right)\right)
$$

where $\Delta$ is the slope of saturation vapor pressure, $R_{n}$ is the net radiation, $G$ is the soil heat flux, $\rho_{a}$ is the mean air density, $c_{p}$ is the specific heat of air, $e_{s}-e_{a}$ is the saturation vapor pressure deficit, $r_{s}$ and $r_{a}$ are the surface and aerodynamic resistances, respectively, $\lambda$ is the latent heat of vaporization, and $\gamma$ is the psychrometric constant.

The equation can be rewritten and simplified to different forms, which usually involve a wind speed at a height of $2 \mathrm{~m}$ (Fu \& Feng 2014). However, because meteorological data are typically obtained from a height of $10 \mathrm{~m}$ and a log transformation would lead to a larger PET result, the original form of Eq. (2) was retained to remove any numerical errors. In total, 7 monthly climatic variables from meteorological records and GCMs, including precipitation, nearsurface wind speed, maximum and minimum air temperatures, near surface relative humidity, total cloud fraction, and surface air pressure are needed to calculate the parameters on the right of Eq. (2).

To prevent 0 or negative PET monthly values from frozen surface soil and large longwave radiation in the cold months, a lower limit of $0.4 \mathrm{~mm} \mathrm{~d}^{-1}$ measured from a high-latitude cold area was used for PET (by Allen et al. 1998). The actual value can be less than 0.4 because a net condensation of water from the atmosphere on the ground is possible. Moreover, 
there were very low or $0 P$ values in the dry winter season over the TP, with no precipitation for more than 2 consecutive months, leading to extremely low $P / P E T$ and high $M$ values. Thus, a lower limit of 0.05 , which is the lower boundary of P/PET for arid regions, as recommended by the United Nations Environment Program, was set for the P/PET values to avoid extreme results (UNEP 1992).

\subsection{Climate data preparation}

The monthly historical climate records since 1966 are available from Anduo meteorological station and were downloaded from the China Meteorological Data Sharing Service System (https://pcmdi.llnl.gov/search/ cmip5). The outputs from 4 GCMs, viz. the Hadley Centre Coupled Model (HadCM3), the Geophysical Fluid Dynamics Laboratory Coupled Physical Model (GFDL-CM3), the Institute Pierre Simon LaplaceCoupled Model 5A-Medium Resolution (IPSL-CM5AMR), and the new Meteorological Research Institute Coupled GCM (MRI-CGCM3), which have fine spatial resolutions and extensive applications, were selected; the spatial resolutions of the 4 projections are $3.75^{\circ}$ (longitude) $\times 2.5^{\circ}$ (latitude), $2.5^{\circ} \times 2^{\circ}, 2.5^{\circ} \times$ $1.27^{\circ}$, and $1.125^{\circ} \times 1.12^{\circ}$, respectively. The Representative Concentration Pathway (RCP) 4.5 emission scenarios were used to represent the moderate temperature increase at the end of the 21st century, in which their historical run and observed records from 19662005 were used as controls, the 'past' future run from 2006-2014 was used to estimate errors, and the near future run from 2015-2035 was used to predict with relatively high confidence.

Estimation of uncertainty is important for any future climate change research. Many uncertainty analyses are based on projected but not historical data, and the predicted parameter value or results can fluctuate to a certain level. The comparison of historical records and GCM runs from 2006-2014 would give a true estimation of the prediction error for each model.

In this study, all 7 GCM variables were spatially downscaled to the meteorological station location by first smoothing its 4 nearby grid values using an inverse distance weighting method (Li et al. 2011). This is necessary because the Anduo meteorological station is located far from the grid center of any of the GCMs. The spatially smoothed data from the GCMs still differ from the historical records, e.g. the precipitation value, which is usually one of best-predicted parameters in GCMs (Fig. 2). The precipitation quantitatively simulated using the MRI-CGCM3 model is

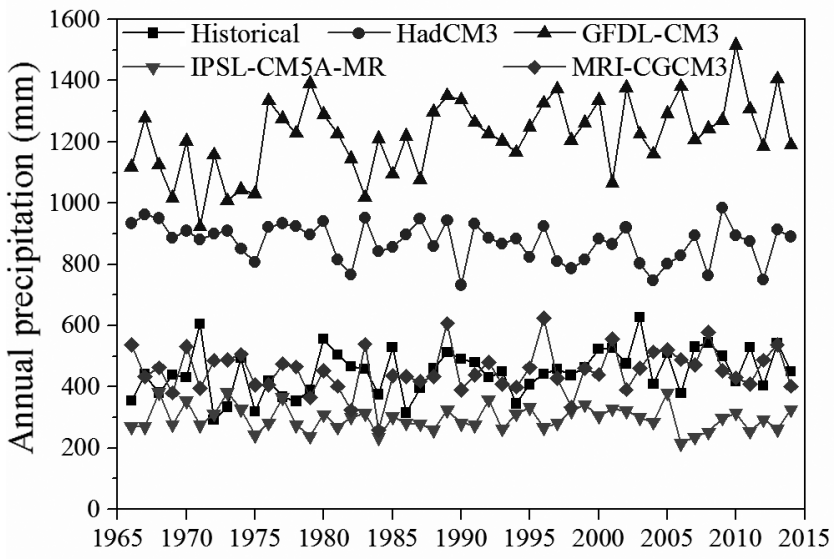

Fig. 2. Precipitation data (observed and simulated by general circulation model, GCM) Anduo from 1966-2014

in closest simulated agreement with the historical data, the IPSL-CM5A-MR model underestimates the historical data by approximately $30 \%$, the HadCM3 model overestimates the data by approximately $100 \%$, and the GFDL-CM3 model overestimates the historical data by $180 \%$.

Statistical techniques with an intuitive and effective use of the transfer function were developed to match the historical and GCM predictions (Zhang 2005, 2007, Cheng et al. 2008, Gunawardhana \& Kazama 2009, Zhang et al. 2011). However, the statistical transfer of 7 parameters involves a large error, whereas ideally it would have the same outcome as the transfer of the final $M$ values. Another advantage of transferring the $M$ values is that the variability of several climate factors within $1 \mathrm{GCM}$ was retained. Here, we fitted 2-parameter univariate transfer functions to the $M$ results for each month and each GCM (12 mo $\times 4$ models) to reduce their differences compared to the observations for the baseline period from 1961-2005. One nonlinear or linear function was built based on quartile plots, where the observational results were plotted on the $y$-axis and the GCM prediction results were plotted on the $x$-axis, meaning that the historical and GCM projections were ranked by pair according to their quartiles instead of their calendar year. The logic behind this representation is that the GCMs predict the trends or extremes of the climate rather than specific values at specific times.

The LAB-fit Software (Universidade Federal de Campina Grande, Brazil) was adapted to automatically search through a pool of 208 functions and produce a list of the top regressions; the regression with the best determination coefficient $\left(\mathrm{R}^{2}\right)$ was selected. The $\mathrm{R}^{2}$ values are higher than 0.94 for all 48 regressions. For each GCM, we could obtain the hindcast 
errors with and without transfer functions at 12 mo and their average as a total error. The transfer functions were then applied to the GCM prediction data for the test period from 2006-2014 and to the future period from 2015-2035. The adjusted and unadjusted GCM results in the test period were compared with historical data to obtain the estimation errors. The 12 monthly dune activity indices in a year were summed together to obtain an annual value. Finally, the trend in the dune activity in Anduo over the TP was estimated according to the results from the 4 GCM future predictions compared to the baseline period.

\section{RESULTS AND DISCUSSION}

\subsection{Historical period estimations}

For the historical baseline period from 1966-2005, all 4 GCMs captured the intra-annual characteristics of the $M$ value, which is low in the summer and much higher from late autumn to the following spring, but the results differ by up to 2 orders of magnitude (Fig. 3). The January $M$ value ranged from 77 to 2069, and the July Mvalue ranged from 3 to 107. Precipitation mainly occurred in the summer, the season with the lowest $M$ value and the only season in the study area with a temperature above $0^{\circ} \mathrm{C}$. The HadCM3 and GFDL-CM3 models underestimate $M$ for all months, while the IPSL-CM5A-MR and MRICGCM3 models overestimate $M$ from June to October. At an annual scale, the MRI-CGCM3 model has the least error compared with the historical records.

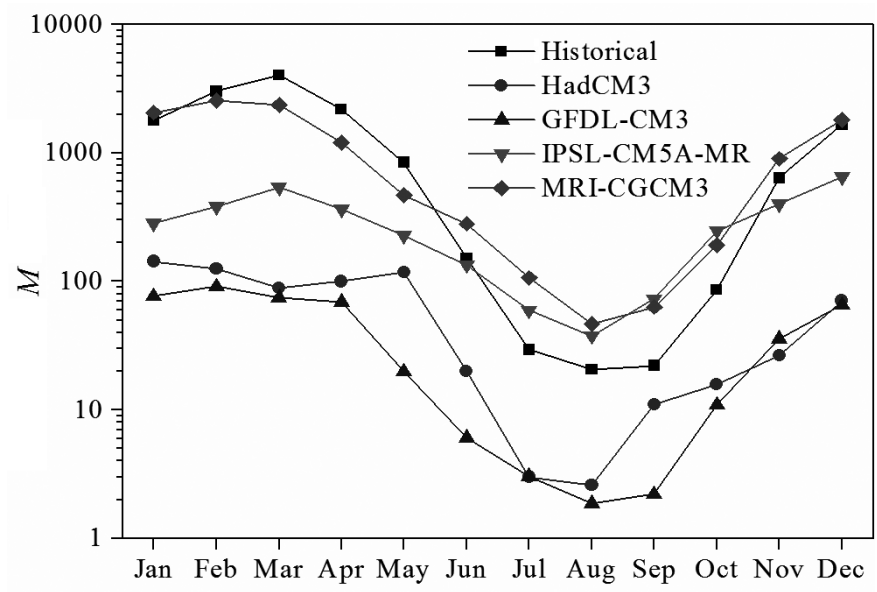

Fig. 3. Intra-annual variation in mean monthly $M$ (dimensionless dune activity index) in historical observations and general circulation model (GCM) projections during the control period 1966-2005
The results show that the GCMs used in this study could be used to analyze dune activity trends. However, a quantitative study is not feasible even using the averages, because of the large differences between their values.

\subsection{GCM downscaling error}

All 4 GCMs reported $>82 \%$ error compared to historical records, and the transfer functions significantly reduced prediction error to $<30 \%$ (Fig. $4 \mathrm{a}$ ). However, when the functions were applied outside of the period for which they were built (i.e. 2006-2014), large estimation errors with an average of $190 \%$ were reported for the $4 \mathrm{GCMs}$ (Fig. 4b). The errors after statistical transfer were larger than in those without transfer functions for 3 of the models; the exception was the MRI-CGCM3 model. This could
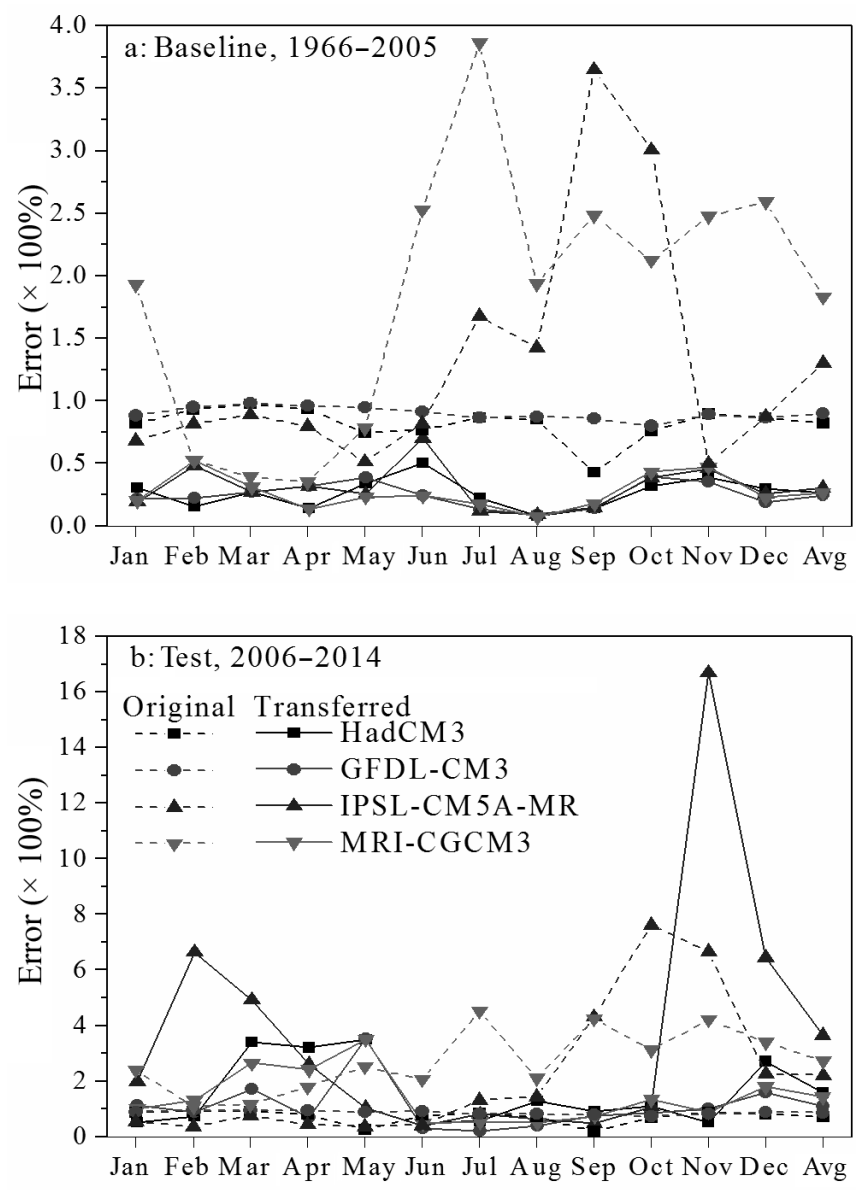

Fig. 4. Differences in $M$ (dimensionless dune activity index) values predicted by the general circulation model (GCM) from historical records in (a) the baseline (1966-2005) and (b) test (2006-2014) periods for each month and their averages (Avg), with and without regression transferring 
be because the test period was short and the GCM projections could be outside the baseline ranges. This may have been the case for the IPSL-CM5A-MR model, but it also indicates that the confidence on downscaling or adjusting GCM predictions based on their statistical relations with historical data may be false due to the irregular nature of climatic factors. Thus, if the functions were applied to GCM future estimations, there would be no quantitative guarantee on the accuracy of the results.

In the original model predictions, the HadCM3 model reported the least error for both the baseline and test periods, followed by the GFDL-CM3 model, whereas the MRI-CGCM3 model showed the largest error between the baseline and test periods. These results indicate that the HadCM3 model captures the best overall climatic parameters on a monthly scale.

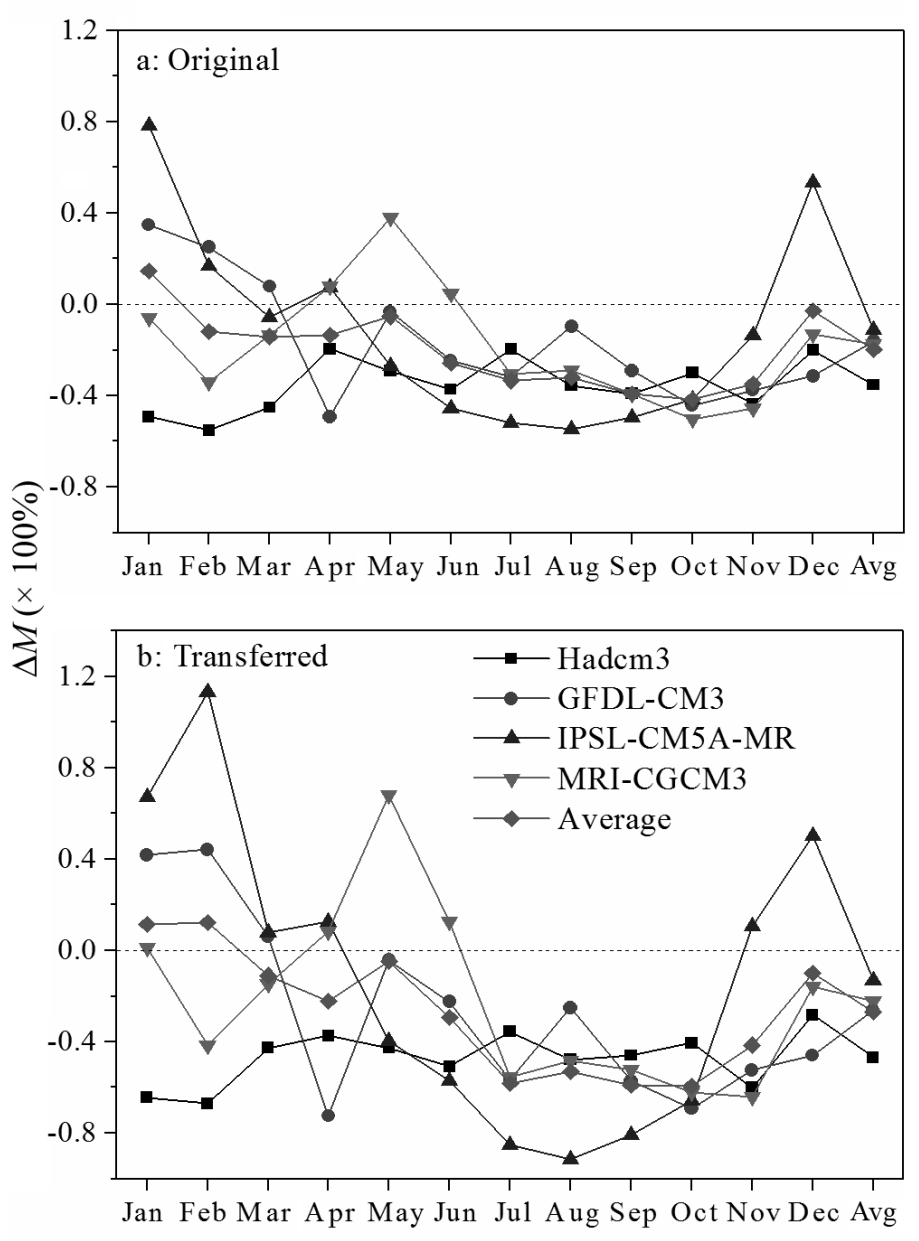

Fig. 5. Predictions (a) without and (b) with transfer functions of the future $M$ (dimensionless dune activity index) values by the 4 general circulation models (GCMs) and their averages in the period 2015-2035 from the baseline period 1966-2005

\subsection{Future changes in the dune activity index}

Although the original and transferred GCM predictions are significantly different from each other quantitatively, both estimations predict that the dune activity indices will decrease. The original average annual reductions in $M$ values from the future period 2015-2035 to the baseline period 1966-2005 are 35, 16,11 , and $18 \%$ for the HadCM3, GFDL-CM3, IPSLCM5A-MR, and MRI-CGCM3 models, respectively (Fig. 5a). The transferred predictions are 2 to $10 \%$ larger (Fig. 5b). This indicates a generally lower annual aeolian activity and desertification pressure in the studied area. Using the original predictions, multiplying the historical monthly $M$ values for the baseline period by the average changing rates for the 4 GCMs resulted in a $9 \%$ reduction in annual $M$ during 2015-2035; a $7 \%$ reduction was obtained with the transfer functions. This can be explained by the decline in surface wind speed and increase in precipitation over the TP (Xu et al. 2008, You et al. 2014). A reduction in the future $M$ value indicates that in the future, there will be more suitable conditions for vegetation and a lower desertification tendency. Taken together with increasing precipitation, the future biological environment will likely improve.

However, the predictions differ at a monthly scale. The HadCM3 model estimates a continuous reduction in $M$ values. The GFDL-CM3 model estimates an increase from January to March; the IPSL-CM5A-MR model shows a continual increase to April; while the MRI-CGCM3 model predicts an increase in $M$ from April to June in the spring season. As a result, the annual aeolian surface activity potential is certain from the 4 GCM models, but its seasonal characteristics are uncertain. The dune activity index is likely to increase in cold and dry January and February, although an overall decreasing annual trend is predicted.

Seasonal variance is important for the desertification and sand dune mobility in this area because surface degradation is most significant in the dry winter and spring, while rainfall is concentrated in the summer which has a limited effect in weakening the annual wind-blown sand activity. The possible acceleration of wind erosion, dune activation, and desertification in the winter is difficult to offset naturally in this harsh local ecosystem.

\section{CONCLUSIONS}

In this study, the future monthly and annual dune activity indices in an area in the Tibetan Plateau 
were estimated by replacing the Thornthwaite evapotranspiration method with the Penman-Monteith equation to reflect more comprehensive environmental conditions. Limits on the PET and P/PET values were added to avoid extremes in the calculations for the long cold and dry seasons.

All of the selected GCMs could hindcast the variations in the dune activity index, but their predicted values had large quantitative errors. The statistical relationships derived from historical records also resulted in large errors, and were not fully applicable to future predictions, so that there is low confidence in adjusted GCM future data. After calculating the average of the $4 \mathrm{GCMs}$, the final trends with and without statistical transfer for the 2015-2035 future period were close to the 1966-2005 baseline period. It is not necessary to adjust the GCM parameters if multi-models and variables are used in similar trend analysis studies.

The average of the 4 GCMs used in the moderate RCP4.5 scenario indicated a 7 to $9 \%$ reduction in the annual dune activity index in the near future before 2035 due to the changing climatic factors including increasing precipitation and declining wind speed. Thus, environmental conditions such as surface degradation and desertification will likely improve in Anduo County, despite the possibility of increased dune activity in the dry and windy winter. It can be inferred that problems of active wind erosion and wind-blown sand in some spots over the TP is a consequence of human disturbance, e.g. road construction and overgrazing, which is reversible if excessive human activities can be managed and reasonable environmental protection policies including enclosure of fragile meadows and rotational grazing can be fully executed. Increases in precipitation and temperature in the future will increase the likelihood of success of remedial practices such as artificial vegetation restoration.

Acknowledgements. This work was supported by the National Science Foundation of China $(41501008,41271216)$, the China Postdoctoral Science Foundation (2014M550518), and the West Light Program for Talent Cultivation of the Chinese Academy of Sciences. Historical climate data were downloaded from the China Meteorological Data Sharing Service System.

\section{LITERATURE CITED}

Allen RG, Pereira LS, Raes D, Smith M (1998) Crop evapotranspiration-guidelines for computing crop water requirements. FAO Irrigation and Drainage Paper 56. FAO, Rome
Chen D, Gao G, Xu CY, Guo J, Ren G (2005) Comparison of the Thornthwaite method and pan data with the standard Penman-Monteith estimates of reference evapotranspiration in China. Clim Res 28:123-132

> Cheng CS, Li G, Li Q, Auld H (2008) Statistical downscaling of hourly and daily climate scenarios for various meteorological variables in South-central Canada. Theor Appl Climatol 91:129-147

> Cheng GD, Wu TH (2007) Responses of permafrost to climate change and their environmental significance, Qinghai-Tibet Plateau. J Geophys Res 112:F02S03, doi: 10.1029/2006JF000631

Collins M, Chandler RE, Cox PM, Huthnance JM, Rougier J, Stephenson DB (2012) Quantifying future climate change. Nat Clim Change 2:403-409

Feng J, Tao W, Xie C (2006) Eco-environmental degradation in the source region of the Yellow River, Northeast Qinghai-Xizang Plateau. Environ Monit Assess 122:125-143

Fu Q, Feng S (2014) Responses of terrestrial aridity to global warming. J Geophys Res 119:7863-7875

Gao Y, Li X, Leung LR, Chen D, Xu J (2015) Aridity changes in the Tibetan Plateau in a warming climate. Environ Res Lett 10:034013, doi:10.1088/1748-9326/10/3/034013

Gunawardhana L, Kazama S (2009) Spatial downscaling of GCM output for assessing the impacts of groundwater temperature in the Sendai Plain. Annu J Hydraul Eng 53: 79-84

Hartmann DL, Tank AMGK, Rusticucci M, Alexander LV and others (eds) (2013) Observations: atmosphere and surface. In: Stocker TF, Qin D, Plattner GK, Tignor M and others (eds) Climate change 2013: the physical science basis. Contribution of Working Group I to the Fifth Assessment Report of the Intergovernmental Panel on Climate Change. Cambridge University Press, Cambridge, p 159-254

Jiang DB, Tian ZP (2013) East Asian monsoon change for the 21st century: results of CMIP3 and CMIP5 models. Chin Sci Bull 58:1427-1435

Kang S, Xu Y, You Q, Flügel WA, Pepin N, Yao T (2010) Review of climate and cryospheric change in the Tibetan Plateau. Environ Res Lett 5:015101, doi:10.1088/17489326/5/1/015101

> King DA, Bachelet DM, Symstad AJ, Ferschweiler K, Hobbins M (2015) Estimation of potential evapotranspiration from extraterrestrial radiation, air temperature and humidity to assess future climate change effects on the vegetation of the Northern Great Plains, USA. Ecol Model 297:86-97

Lancaster N (1988) Development of linear dunes in the southwestern Kalahari, southern Africa. J Arid Environ 14:233-244

- Li X, Jin R, Pan X, Zhang T, Guo J (2012) Changes in the near-surface soil freeze-thaw cycle on the QinghaiTibetan Plateau. Int J Appl Earth Obs Geoinf 17:33-42

> Li Z, Liu WZ, Zhang XC, Zheng FL (2011) Assessing the sitespecific impacts of climate change on hydrology, soil erosion and crop yields in the Loess Plateau of China. Clim Change 105:223-242

Selbig WR (2015) Simulating the effect of climate change on stream temperature in the Trout Lake Watershed, Wisconsin. Sci Total Environ 521-522:11-18

Sivakumar MVK (2007) Interactions between climate and desertification. Agric For Meteorol 142:143-155

Thomas DSG, Knight M, Wiggs GFS (2005) Remobilization of southern African desert dune systems by twenty-first 
century global warming. Nature 435:1218-1221

UNEP (United Nations Environment Program) (1992) World atlas of desertification. Edward Arnold Publishers, London

Wang X, Yang Y, Dong Z, Zhang C (2009) Responses of dune activity and desertification in China to global warming in the twenty-first century. Global Planet Change 67:167-185

Wang C, Zhang L, Lee SK, Wu L, Mechoso CR (2014) A global perspective on CMIP5 climate model biases. Nat Clim Change 4:201-205

Xu ZX, Gong TL, Li JY (2008) Decadal trend of climate in the Tibetan Plateau-regional temperature and precipitation. Hydrol Process 22:3056-3065

Xue X, Guo J, Han BSA, Sun QW, Liu LC (2009) The effect of climate warming and permafrost thaw on desertification in the Qinghai-Tibetan Plateau (SCI). Geomorphology 108:182-190

Yang M, Wang S, Yao T, Gou X, Lu A, Guo X (2004) Desertification and its relationship with permafrost degradation in Qinghai-Xizang (Tibet) plateau. Cold Reg Sci Technol 39:47-53

Editorial responsibility: Eduardo Zorita, Geesthacht, Germany
Yao T, Thompson L, Yang W, Yu W and others (2012) Different glacier status with atmospheric circulations in Tibetan Plateau and surroundings. Nat Clim Change 2:663-667

You Q, Fraedrich K, Min J, Kang S, Zhu X, Pepin N, Zhang L (2014) Observed surface wind speed in the Tibetan Plateau since 1980 and its physical causes. Int J Climatol 34:1873-1882

Zhang K, Qu J, Han Q, An Z (2012) Wind energy environments and aeolian sand characteristics along the Qinghai-Tibet Railway, China. Sediment Geol 273-274: 91-96

Zhang XC (2005) Spatial downscaling of global climate model output for site-specific assessment of crop production and soil erosion. Agric For Meteorol 135:215-229

> Zhang XC (2007) A comparison of explicit and implicit spatial downscaling of GCM output for soil erosion and crop production assessments. Clim Change 84:337-363

Zhang XC, Liu WZ, Li Z, Chen J (2011) Trend and uncertainty analysis of simulated climate change impacts with multiple GCMs and emission scenarios. Agric For Meteorol 151:1297-1304

Submitted: July 31, 2015; Accepted: February 23, 2016

Proofs received from author(s): May 4, 2016 